\title{
تأثير تدريبات السرعة Spd3 على بعض المتغيرات البدنية
}

\section{المقدمة ومشكلة البحث :}

تعتبر السباحة أحدى الرياضات الرقمية التي يخضع ممارسيها لتدربيات مكثفة والسباح في هذا المجال يكافح ويستميت في التدريب من أجل بضع ثوان تفرق بينه وبين أقرانه في سبيل تحقيق الفوز بمستوى رقمي أفضل، في جزء من الثانية قد يحقق رقم قياسيا جديدا وقد يتوقف لهن عليه مركز أو ميدالية، ولكي يستطيع السباح تحقيق مستوى رقمي أفضل وتحسين مستوى الأداء لابد من اتباع أساليب التدريب الحديثة والمتطورة التي تعمل على تتمية عناصر القوة والسرعة لدى السباح. فالسرعة هي القدرة على أداء حركات منتابعة من نواع واحد في أقصر فترة زمنية. فتعتبر من العوامل الرئيسية للأداء البدني والتي ترنبط بتتابع الانقباض العضلي عند الأداء الحركي، وهو المكون الأساسي لمعظم الأنشطة الرياضية وخاصة المرتبطة بزمن الأداء الحركي. وتؤئز

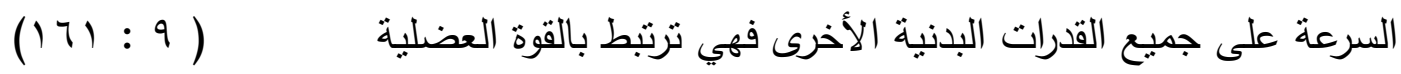

ئئويشير محمد علي القط (1 . . rم) أن ندريب السرعة من أنواع التدريب الأساسية والهامة من الوجهة الفسيولوجية ومن ناحية تمثيل الطاقة للسباحة بصفة عامة وسباحي السرعة بصفة خاصة، وبعتمد تدريب السرعة على استخدام لتدريب اللاهوائي وفي هذه الطريقة يطلب من

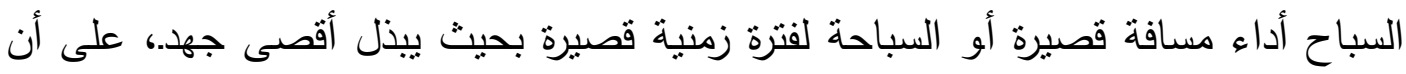
تكون فترات الراحة بين المجموعات كبيرة بقدر معقول يسمح للسباح باستعادة الاستشفاء $(191: 11)$ ويعينه على مواصلة التدريب وبذل الجهد للمجموعات التالية

ويرى أبو العلا عبد الفتاح وحازم حسين سالم (11 +rr) إن تطوير السرعة الحقيقي يأتي من خلال التركيز على السباحة بسرعة أكثر من محاولة التركيز على زيادة الجهد بشدة وضرورة أن بتدرب السباح بسرعة في التدريب حتى يسرع في السباق، ويهنم بأداء كل دوران وبدء وكل (00: $r)$

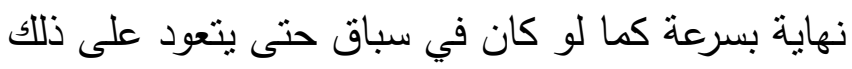




\section{العدد التاسع _ البحث الخامس}

ويذكر جوت كروب Jot Crop نقلا عن أبو العلا عبد الفتاح وحازم حسين سالم (1) أنه خلال العشر سنوات القادمة فإن التحسن في المستوى الرقمي في السباحة سوف يصل إلى 0- ( \% زيادة في تدريبات القدرة الهوائية وحوالي · r من تدريبات الفدرة اللاهوائية، وهذا يعني أن هنالك اتجاه إلى تدريبات السرعة (القدرة اللاهوائية) في برامج التدريب في الاعوام (or : r) القادمة، ولكن هذا لا يعني تقليل من القدرة الهوائية

وتدريب speed 3 داخل الماء يزيد مقدار ATP - PC في الألياف العضلية المتدربة كوزيادة القوة العضلية ،وزيادة معدل تتمية القدرة داخل العضلات ،وزيادة معدل وشكل استثارة الألياف العضلية للانقباض عن طريق الجهاز العصبي ، وتعمل كل هذه التكيفات على زيادة قدرة أداء السباحات المختلفة ،فعند التخطبط يجب أن يثمل التدريب على مقادير كافية منه كجزء من خطة التدريب خلال مراحل الموسم التدريبي المختلفة ، فهو لا يحتاج الكثير من الوقت ، لذا فإنه يسهل وضعه داخل الخطة الأسبوعية دون التأثير سلبا على طرق التدريب الأخرى ، كما يجب على السباحين استخدام هذا النوع من التذريب في الفترة المبكرة من الموسم حتى يمكنهم زيادة قدرتهم على السباحة قبل البدء في الاهتمام بتدريب تحمل اللاكتيك متك ، كما يجب الاستمرار في المحافظة على تلك القدرة التي اكتسبوها بحيث تصبح هي الهدف الرئيسي للخطة التدريبية خلا الجزء الأوسط من الموسم ، كما يجب أن تكون هدفا رئيسيا $(1 \wedge): Y T)$ في الجزء الأخير من الموسم •

وقد لاحظ الباحث من خلا اطلاعه على العديد من الدراسات ، ومتابعة العديد من التدريبات والبطولات أن تدريب القدرة لتتمية السرعة (Spd3) من افضل الاساليب فى تحسين عنصرى القدرة والسرعة بشكل أساسي وهما من اكثر العناصر المؤثرة على سباقات المسافات القصيرة ، ويفيد في أعطاء السرعة القصوى لمرحلتي البدء والدوران ومرحلة إنهاء السباق ، مما يجعل أهمية تدريب القدرة لتتمية السرعة ليس فقط للمسافات القصيرة وإنما أيضا للمسافات المتوسطة والطوبلة ، وزيادة قدرة السباحين على الوصول لأقصى سرعة مبكرا في لذي بداية السباق ، ومما سبق راءا الباحث اهمية فى التعرف على تأثير تدريبات السرعة Spd3 على بعض المتغيرات البدنية فى سباحة الفراشة. 
يهدف البحث الى التعرف على تأثير تدريبات السرعة Spd3 على بعض المتغيرات البدنية لاى ناشئى سباحة الفراشة فروض البحث:

توجد فروق دالة إحصائية بين القياسات القبلية والبعدية فى بعض المتغيرات البدنية لسباحى الفراشة مجموعة البحث التجربيية. توجد فروق دالة إحصائية بين القياسات القبلية والبعدية فى بعض المتغيرات البدنية لسباحى الفراشة مجموعة البحث الضابطة .

- - توجد فروق ذات دلالة احصائية بين متوسطى القياسين البعديين لاى مجموعتى البحث التجريبية والضابطة فى بعض المتغيرات البدنية لسباحى الفراثة ولصالح مجموعة البحث التجريبية.

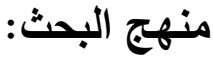

استخدم الباحث المنهج التجريبي كنهج مناسب للاراسة باستخدام القياس القبلي والبعدي لمجموعتين احدهما تجريبية والأخرى ضابطة.

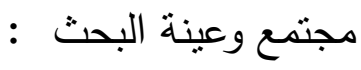

اختيرت عينة البحث بالطريقة العددية من السباحين البراعم الذكور الممارسين لسباحة الفراثة بنادي العربى الكويتى والمسجلين في الاتحاد الكويتى للسباحة للموسم الرياضي Y. V V. تضمنت الدراسة (TY) سباحًا وقد تم تقسيمهم عثوائيا بالتشاوي إلى مجموعتين وقد اشتملت كل مجموعة على (rا) سباحًا ، بالاضافة الى (^) ناشئين لاجراء الدراسة الاستطلاعية للبحث. 


\section{العدد التاسع _ البحث الخامس}

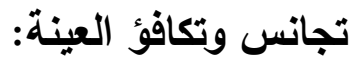

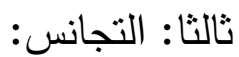

قام الباحث بإجراء التجانس على عينة البحث البالغ عددها (YT) سباحًا (r) سباحًا للمجموعة التجريبية و (r ( ) سباحًا للمجموعة الضابطة في متغيرات (السن، الطول، الوزن) بالاضافة الى الى (^) سباحين لاجراء الدراسة الاستطلاعية للبحث كما يوضحه جدول رقم

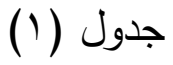

المتوسط الحسابي والإنحراف المعياري ومعامل الالنواء لقياسات السن والطول والوزن ومتغيرات الصفات البدنية قيد البحث

\begin{tabular}{|c|c|c|c|c|c|}
\hline معامل الالتوء & الوسيط & الانحراف المعباري & المتوسط الحسابي & وحدة القياس & المتغيرات \\
\hline$\lambda r-, l$ & $r, 1$. & $1 \wedge$, & $(1,1$. & السنة & 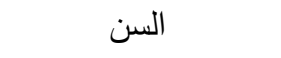 \\
\hline 19, & ro,r. & $v 1,1$ & $\varepsilon\rceil, \Gamma$. & كجم & الوزن \\
\hline$r q, 1$ & $0,1 M$ & r^, $\cdot$ & IT,IT & سم & الطول \\
\hline $.0 Y$ & r,^o & $\cdot, 11$ & $\ulcorner, \wedge \vee$ & سنة & العمر التدريبى \\
\hline .,., & $10,0$. & $\cdot, Y_{1}$ & $10,0 \mathrm{r}$ & عدد/ث & قدرة عضلات الذراعين \\
\hline .,. or & 1,10 & $\cdot, \cdot Y I$ & 1,17 & متز & قدرة عضلات الرجلين \\
\hline$\cdot, \cdots \leqslant V$ & $I V, r$. & $\cdot, 11$ & IV,Yr & عدد/ث & قدرة عضلات الظهر \\
\hline צד & $r, T$. & $\cdot, I V$ & 14,70 & عدد/ث & قدرة عضلات البطن \\
\hline
\end{tabular}




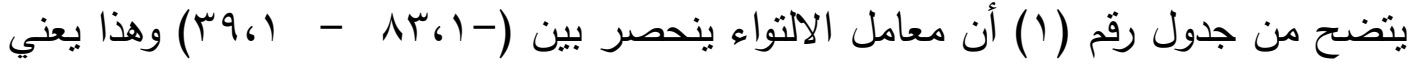
أن المتغيرات تحقق المنحنى الاعتدالي حيث تتحصر ما بين +1 مما يؤكدا على مدى التجانس بين أفراد العينة ككل في السن والطول والوزن والعمر التدريبي ومستوى بعض بـ الصفات البدنية لاى ناشئى سباحة الفراشة.

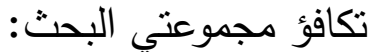

تم إجراء التكافؤ بين مجموعتي البحث التجريبية والضابطة في المتغيرات البدنية لأفراد عينة البحث وجدول رقم (r) يوضح ذلك.

$$
\text { جدول (r) }
$$

المتوسط الحسابي والانحراف المعياري وقيمة "ت" في متغيرات الصفات البدنية لاى ناشئى سباحة الفراثة قيد البحث

\begin{tabular}{|c|c|c|c|c|c|c|c|}
\hline \multirow[t]{2}{*}{ مستوى الدلالة } & \multirow[t]{2}{*}{ قيمة "ت" } & \multicolumn{2}{|c|}{ المجموعة الضابطة } & \multicolumn{2}{|c|}{ المجموعة التجريبية } & \multirow[t]{2}{*}{ وحدة القياس } & \multirow[t]{2}{*}{ المتغيرات } \\
\hline & & $\varepsilon$ & s & $\varepsilon$ & ? & & \\
\hline غير دال & س ז & T & $10, \varepsilon$. & $\cdot, 11$ & $10,\{\Lambda$ & عدد/ث & قدرة عضلات الذراعين \\
\hline غير دال & •, or & $\cdot, 11$ & 1,17 & $\cdot, r)$ & 1,10 & متر & قدرة عضلات الرجلين \\
\hline غير دال & $\cdot, \cdot 1 \leq$ & $\cdot, \sum V$ & $I V, I T$ &.,$I V$ & $1 v, 10$ & عدد/ث & قدرة عضلات الظهر \\
\hline غير دال & $\cdot, Y_{1}$ & Tr & $1 r, 00$ & $\cdot, 1 \leq$ & Ir,T. & عدد/ث & قدرة عضلات البطن \\
\hline
\end{tabular}

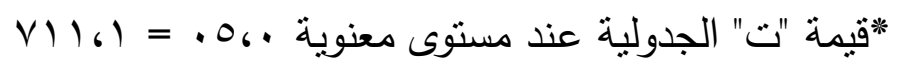

يتضح من الجدول (r) بأن قيم "ت" غير دالة حيث كانت جميعها أقل من قيم "ت" الجدولية عند مستوى معنوية ، ،0. ويشير ذلك إلى تكافؤ أفراد عينة البحث في متغيرات البحث 


\section{العدد التاسع _ البحث الخامس}

أدوات ووسائل جمع البيانات

لجمع البيانات الخاصة بالبحث، أستعان الباحث بالأدوات والاختبارات التالية: - 1أدوات خاصة لقياس متغيرات النمو : أ-استخدام جهاز الرستاميتز لقياس الطول بالسنتيمنر . ب- استخدام الميزان الطبي لقياس الوزن بالكيلو جرام. - 2أ- اختبار ثنى الذراعين عرضا لقياس القدرة العضلية للذراعين فى (•r)ث. ب- اختبار الوثب العريض عرضا لقياس القدرة العضلية للرجلين. ج- اختبار الجلوس من الرقود لقياس القدرة العضلية للبطن. د - اختبار رفع الجذع لاعلى لقياس القدرة العضلية للظهر . التدريبات المقترحة: هدف التدريب: - 1 - 20

تأثير تدريبات السرعة Spd3 على بعض المتغيرات البدنية والمستوى الرقمى لدى سباحى الفراشة.

الأسس العلمية للبرنامج التالية : 


\section{العدد التاسع _ البحث الخامس}

ملائمة التدربيات للمرحلة السنية - الخصوصية - عدد التكرارات والمسافات - فترات الراحة البينية - مبدأ الاستمرارية في التدريب.

\section{تنفيذ تجربة البحث:}

تم تتفيذ التدريبات المقترحة في صورتها النهائية في حمام سباحة نادي العربى الكويتى في

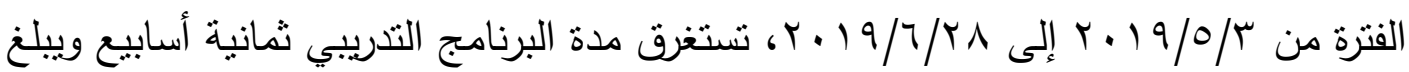

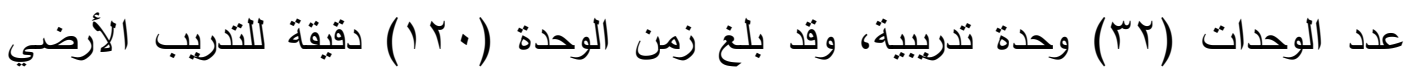
والمائي معًا. بواقع • بق للتدريب الأرضي و ·9 ق للتدريب المائي ، وجدول (ع) بوضح التوزيع الزمني للوحدة التذريبية للمجموعتين التجريبية والضابطة. وتم تطبيق البرنامج المقترح أيام السبت والأثثين والأربعاء والخميس من كل اسبوع لرهد

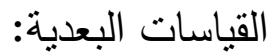

بعد الانتهاء من تطبيق التدربيات المقترحة أجريت القياسات البعدية لمجموعتي البحث وقام الباحث بإجراء القياسات البعدية بنفس الاسلوب والظروف التي تمت بها القياسات القبلية وسجلت النتائج والبيانات التي تم التوصل إليها في نفس الاستمارات الخاصة بأفراد العينة والتي سجلت فيها نتائج القياسات القبلية لمعالجتها إحصائيا بهدف التوصل إلى النتائج التي

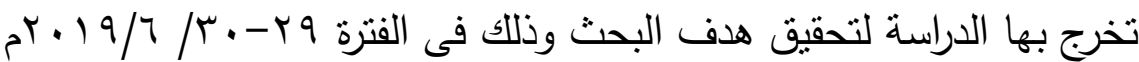
المعالجات الإحصائية المستخدمة:

لتحقيق أهداف البحث وفروضه، تم استخدام الأساليب الإحصائية التالية:

المتوسط الحسابي.

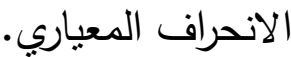

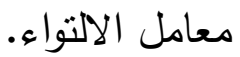




\section{مجلة العلمية لعلوم التربية البلنية والرياضية المتخصصة}

\section{العدد التاسع _ البحث الخامس}

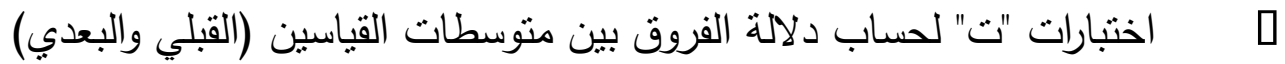
للمجموعتين ( التجريبية والضابطة) في متغيرات موضع الدراسة.

النسبة المئوية لمقدار التحسن.

عرض النتائج ومناقثتها

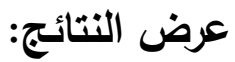

\section{جدول (r) (ب)}

دلالة الفروق بين القياسين القبلي والبعدي للمجموعة التجريبية في متغيرات بعض المتغيرات
ن
والبدنية لناشئى سباحة . . 1 متر فراشة

\begin{tabular}{|c|c|c|c|c|c|c|c|c|}
\hline \multirow[t]{2}{*}{ قيمة "ت" } & \multirow[t]{2}{*}{ نسبة التغير \% } & \multirow{2}{*}{ الفروق بين } & \multicolumn{2}{|c|}{ القياس البعدي } & \multicolumn{2}{|c|}{ القياس القبلي } & \multirow{2}{*}{ وحدة القياس } & \multirow[t]{2}{*}{ المتغيرات } \\
\hline & & & $\varepsilon$ & s & $\varepsilon$ & 5 & & \\
\hline$\varepsilon, T^{2}$ & $\% \curlyvee \varepsilon, \wedge$. & $\Gamma, \wedge \varepsilon$ & זr, & 19,r & $\cdot, 11$ & $10, \varepsilon \wedge$ & عدد/ث & قدرة عضلات الذراعين \\
\hline$\varepsilon, r_{1}$ & $\%$ \%r,q1 & $\cdot, r q$ & $\cdot, 11$ & $1,0 \leqslant$ & $\cdot, Y_{1}$ & 1,10 & 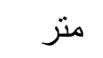 & قدرة عضلات الرجلين \\
\hline$\varepsilon, 79$ & $\%$ \%ч,, 7 & $\varepsilon, \varepsilon \vee$ & $\cdot$, Or & rI,Tr & $\cdot, I V$ & $1 V, 10$ & عدد/ث & قدرة عضلات الظهر \\
\hline$\varepsilon, Y$, & $\% r, 11$ & r,qr & $\cdot, Y_{1}$ & $17,0 Y$ & $\cdot, 1 \leq$ & Ir,T. & عدد/ث & قدرة عضلات البطن \\
\hline
\end{tabular}

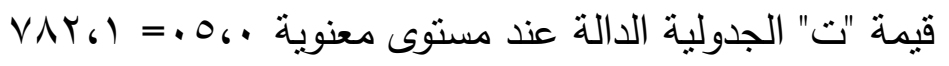

يتضح من جدول رقم (r) وجود فروق دالة إحصائيا لصالح القياس البعدي لعينة البحث في المتغيرات البدنية لسباحى ( · ( ) فراشة قيد البحث. 


\section{مجلة العلمية لعلوم التربية البدنية والرياضية المتخصصة}

\section{العدد التاسع _ البحث الخامس}

جدول (§)

دلالة الفروق بين القياسين القبلي والبعدي للمجموعة الضابطة في متغيرات بعض المتغيرات $1 r=\dot{0}$ البدنية لناشئى سباحة . . 1 منر فراشة

\begin{tabular}{|c|c|c|c|c|c|c|c|c|}
\hline \multirow{2}{*}{ "تيمة } & \multirow{2}{*}{ التغبر \% نسبة } & \multirow{2}{*}{ الفتروسطين } & \multicolumn{2}{|c|}{ القياس البعدي } & \multicolumn{2}{|c|}{ القياس القبلي } & \multirow[t]{2}{*}{ وحدة القياس } & \multirow[t]{2}{*}{ المتغيرات } \\
\hline & & & $\varepsilon$ & s & $\varepsilon$ & r & & \\
\hline$r, 10$ & $\% \backslash 1, \wedge 1$ & I,AT & זד, & WV,YY & 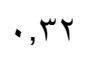 & $10, \varepsilon$. & عدد/ث & قدرة عضلات الذراعين \\
\hline$r, \wedge \vee$ & $\% 11, r$. & • וT & $\cdot, Y_{1}$ & $1, r 9$ & $\cdot, 11$ & 1,17 & 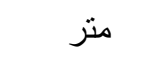 & قدرة عضلات الرجلين \\
\hline$r, r$ r & $\% \backslash Y, Y\}$ & $r, 1$. &., $1 \leq$ & $19, Y Y$ & $\cdot, \leqslant \vee$ & IV,IY & عدد/ث & قدرة عضلات الظهر \\
\hline$r, r_{1}$ & $\% \varepsilon r, \varepsilon \vee$ & ט & $\cdot, r r$ & $1 \leqslant, \wedge \wedge$ & 更 & $1 r, 00$ & عدد/ث & قدرة عضلات البطن \\
\hline
\end{tabular}

VAY6) = قيمة "ت" الجدولية الدالة عند مستوى معنوية .06

يتضح من جدول رقم (؟) وجود فروق دالة إحصائيا لصالح القياس البعدي لعينة البحث في المتغيرات البدنية والفسيولوجية ومستوى الاداء المهارى لسباحى ( . . () فراشة قيد البحث. 


\section{العدد الثاسع _ البحث الخامس}

\section{(0) (0دول}

دلالة الفروق بين القياس البعدي للمجموعة التجريبية والضابطة في بعض المتغيرات

ن ن

البدنية لناشئى سباحة . . 1 مثر فراشة

\begin{tabular}{|c|c|c|c|c|c|c|}
\hline \multirow[t]{2}{*}{ قيمة "ت" } & \multicolumn{2}{|c|}{ المجموعة الضابطة } & \multicolumn{2}{|c|}{ المجموعة التجريبية } & \multirow[t]{2}{*}{ وحدة القياس } & \multirow[t]{2}{*}{ المتغيرات } \\
\hline & $\varepsilon$ & 5 & $\varepsilon$ & 5 & & \\
\hline r, ro & אזד, & IV,YY & • & $19, \pi r$ & عدد/ث & قدرة عضلات الذراعين \\
\hline$r, 79$ & $\cdot, r_{1}$ & $1, r q$ & $\cdot, 11$ & $1,0 \leqslant$ & متز & قدرة عضلات الرجلين \\
\hline$r, 0 \leqslant$ & $\cdot, 1 \leqslant$ & $19, Y Y$ & . Or & rI,Tr & عدد/ث & قدرة عضلات الظهر \\
\hline$r, r$ r & 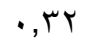 & $1 \leqslant, \wedge \Lambda$ & $\cdot, r)$ & 17,04 & عدد/ث & قدرة عضلات البطن \\
\hline
\end{tabular}

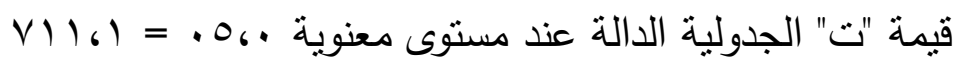

يتضح من جدول رقم (0) وجود فروق دالة إحصائيا بين مجموعتي البحث التجريبية والضابطة في مستوى بعض المتغيرات البدنية قيد البحث لصالح المجموعة التجريبية. ثانيا: مناقتشة وتفسير النتائج:

يتضح من نتائج الجدول رقم (ب) وجود فروق دالة بين القياسين القبلي والبعدي لصالح القياس البعدي للمجموعة التجريبية في متغيرات البدنية المقاسة المتمثلة في قدرة عضلات الرجلين والظهر والبطن والذراعين. 


\section{العدد التاسع _ البحث الخامس}

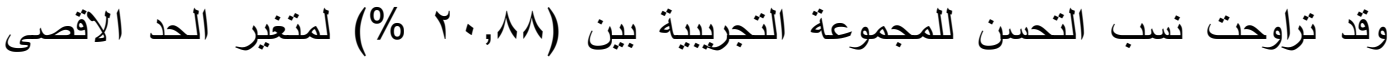

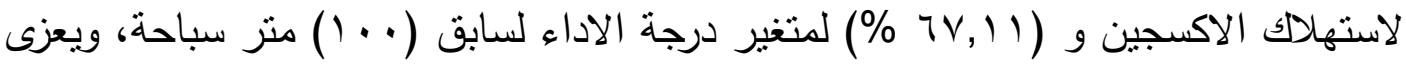
الباحث تلاك الدلائل بالنسبة للمجموعة التجربيية إلى التدربيات المقترحة أن لها تأثنر على قوة

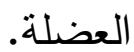

وتتفق نتائج هذه الدراسة مع مختار إبراهيم(T · . rم) أن صفة القدرة الهوائية لها الدور الكبير في السباحة ولا سيما عند ظهور عامل التعب الناتج عن أداء الواجبات البدنية والمهارية والخططية لذا فان تطورها وفق جاءت من خلال استخدام التمارين التخصصية باستخدام شدة وزمن وفترة دوام المثير للطريقة التثريبية الخاصة بنلك الصفة وهى تدريبات (En1 - En2) فضالا عن استخدام تدريبات القدرة اللاهوائية الخاصة بالسباحة منل تدريبات - Sp1 ) (Sp2)

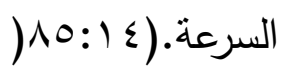

كما يتضح من نتائج جدول رقم (ع) وجود فروق دالة بين القياسين القبلي والبعدي لصالح القياس البعدي للمجموعة التجريبية في متغيرات البدنية ويعزى الباحث التحسن في المتغيرات المهارية إلى تطبيق التدريبات المقترحة للسرعة لدورها في تحسين المستوى الرقمي لسباحي · · ام فراشة ويؤكد Sheila Taormina (2013) أن ثتمية عنصر السرعة من أهم الصفات البدنية المؤثرة على أداء السباح وله أهية واضحة في تحسين المستوى الرقمي.

$$
\text { TIT:YO) }
$$

وتتفق نتائج هذه الدراسة مع دراسة ضحى فتحي (1) (1)(^) ، محمد إبراهيم

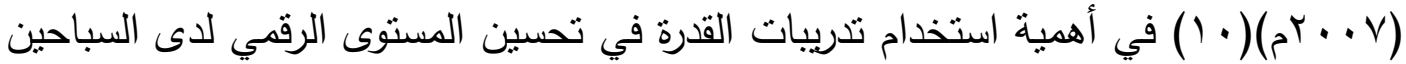
خلا فترة الإعداد البدني الخاص وفترة ما قبل المنافسات وبذلك يكون قد تحقق الفرض الأول والذي ينص على نؤثر طريقة تدريب القدر SP3 على المستوى الرقمي لسباحة الزحف تأثثر ايجابيا. 
كما يتضح من نتائج جدول رقم (ع) وجود فروق دالة بين القياسين القبلي والبعدي لصالح القياس البعدي للمجموعة الضابطة ويرجع الباحث هذا التحسن البسيط للمجموعة الضابطة إلى أن البرنامج التقليدي الذي طبق على المجموعة الضابطة لا يحدث تغيرات ملحوظة، وقد أوضح ذلك تفاوت نسبة التغير بين المجموعتين التجريبية والضابطة في مستوى الأداء وزمن السباحة ( . . () متر فراشة، مما يشير إلى أهمية تدريبات السرعة في تطوير الأدءا وتحسين سرعة السباحة.

كما يعزى الباحث أيضا التقدم غبر ملحوظ الحادث للمجموعة الضابطة أيضا إلى الانتظام في التدريب حيث أكد (2011) Blythe Lucero أن الانتظام في التدريب يؤدي إلى تحسن وظائف الجسم وينعكس ذلك إيجابيا على قدرات وأداء السباح. (1) : (r. (

والجدير بالذكر أن نسب التحن للمجموعة الضابطة في المتغيرات البدنية كانت أقل من نسب التحسن لمثيلاتها في المجموعة التجريبية. وهذا يؤكد أن البرنامج التدربيي المقترح كان له تأثيرا فعالا على تتمية المتغيرات البدنية. وتتفق هذه النتائج مع دراسة طارق محمد عبد الوهاب (ع ا ـ r) التي تؤكد أن تدريبات السرعة تحسن بعض القدرات البدنية منها القوة العضلية وتحمل السرعة (^) الإسنتتاجات

من خلال النتائج التي توصل إليه هذا البحث توصل الباحث إلى الاستتناجات التالية: - 1 -

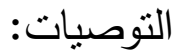
وفي ضوء مناقثة نتائج البحث وفي حدود العينة يوصي الباحث بما يلي: 
مجلة العلمية لعلوم التربية البانية والرياضية المتخصصة

العدد التاسع _ البحث الخامس

- 1- 1 وضع تدريبات السرعة ضمن البرنامج التقليدي الذي يطبق على البراعم في الأندية الرياضية لكي يرفع من مستوى الكفاءة البدنية لديهم.

-2 يادة التدريبات الخاصة بسباحة الفراشة لتطوير المستوى الرقمي للسباحين.

-3 3 الاسترشاد بنتائج هذا البحث في إجراء مزيد من الدراسات لوضع تدريبات داخل وخارج الماء تسهم في رفع المستوى المهاري والرقمي للسباحات الأخرى. 


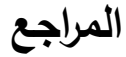

\section{أولا: المراجع العربية}

-1أبو العلا عبد الفتاح ( . . . ץ): تدريب السباحة للمستويات العليا، دار الفكر العربي،

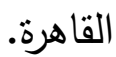

-2أبو العلا عبد الفتاح، حازم حسين سالم (1 (1 + ): الاتجاهات المعاصر في تدريب السباحة، دار الفكر العربي.

-3الحسيني فراج رمضان فراج ( • ( • ( ) تأثير تدريبات السرعة المتغيرة باستخدام بعض الوسائل التدريبية على المستوى الرقمي لسباحي الظهر ، رسالة ماجيستير غير منشورة، كلية التربية الرياضية، قسم التدريب الرياضي، جامعة المنيا.

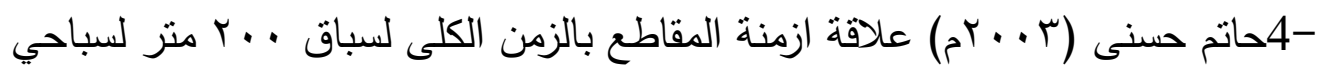
المستوى العالي ، المجلة العلمية علوم و فنون الرياضة كلية تربية رياضية جامعة حلوان

-5حسين درى أباظة ( . . . ץم): فاعلية استخدام مجهود بدني مختلف الثدة على الكفاءة الوظيفية للجهاز الدوري التتفسي للسباحين، مجلة بحوث التربية الرياضية، المجلد بr، العدد ـ 0، أغسطس، كلية التربية الرياضية للبنين، جامعة الزقازيق.

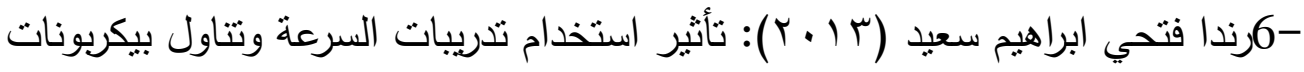
الصوديوم على التعب ومستوى الأداء في السباحة، رسالة دكتوراه غير منشورة، كلية تربية رياضية بنات، رياضات المائية والمنازلات، جامعة الزقازيق.

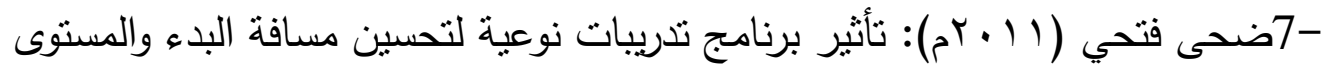
الرقمي في سباحة الزحف على البطن ، رسالة ماجستير ، كلية تربية رياضية ، جامعة طنطا 


\section{العدد التاسع _ البحث الخامس}

-8طارق محمد عبد الوهاب محمد (ع ا • Y): أثز استخدام أساليب تدريب السرعة على المستوى الرقمي لسباحي •0 منر حرة، رسالة ماجستير غير منشورة، كلية التربية الراضية، النظريات وتطبيقات الرياضيات المائية، رياضات المائية والمنازلات، جامعة بنها. -9عام عبد الخالق(ץ . ץ): التدريب الرياضي نظريات-نطبيقات، دار منشأة المعرف،

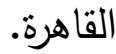

-10ماهر أحمد عاصي، مصطفى حميد محمد (9 +. ب): الاسس العلمية لتعليم السباحة والتدريب عليها، دار الثؤون الثقافية العامة، بغداد

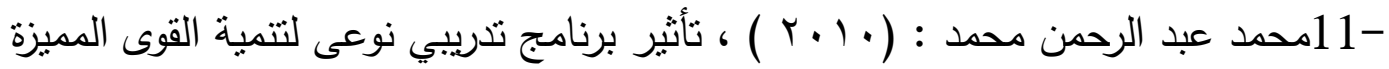
للسرعة داخل الماء على بعض المتغيرات الكينماتيكية و المستوى الرقمي لسباحي الفراشة ، رسالة دكتوراه ، كلية تربية رياضية ، جامعة المنصورة.

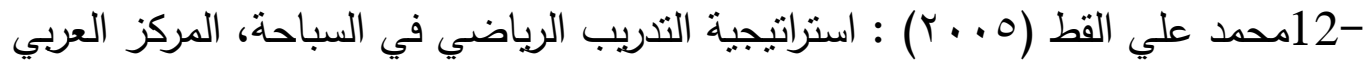
للنشر، الجزء الثاني. القاهرة.

-13محمد علي القط. المباديء العلمية للسباحة ( ( . ب): دار القبص للطباعة وفصل الألوان، طب، القاهرة.

-14مختار ابراهيم عبد الحافظ (T . . rم) تقويم خطط السباحة لسباحي المسافات القصيرة، رسالة دكتوراه غير منشورة ، كلية التربية الرياضية بنين جامعة بنها.

-15مصطفي كاظم مختار، أبو العلا أحمد عبد الفتاح، أسامة كامل راتب(9919 (م):"السباحة من البداية إلى البطولة"، دار الفكر العربي، القاهرة. 
-16 نفين امين العفيفي (rا • ب م) تأثير تدريب القدرة "SP3" على المستوى الرقمي للسباحين الناشئين ،بحث علمي منشور، مجلة بحوث التربية الرياضية، كلية التربية الرياضية للبنين، جامعة الزقازيق.

-17 هبة حلمي الجمل(0 ץ): استخدام أساليب مختلفة لتطوير مهارة البدء من أعلى في السباحة، رسالة دكتوراه غير منشورة، كلية التربية الرياضية، جامعة طنطا.

\section{ثانيًا: المراجع الأجنبية}

18. Blythe Lucero (2011): Strength Training for Faster Swimming, Meyer\& Meyer Verlag,.p21

19 -Fina swimming manual (1999) : The Freestyle stroke drills Isit fina swimming manalp.

20. Lerdo,R,Cardelli(2003): "Breathing and Propelling in Crawlas A function of Skill And Swim Velocity" international -of sports Medicine, 24(1), Jan, 75-80.

21. Mark Durnford (2014): Front Crawl Drills and Land Training, Sports \& Recreation. P77

22 - Maglischo W.Erenst (1993) : Swimming even Faster Newzealand Human. Kinatice. 